\title{
Blue rubber bleb nevus syndrome
}

Blue rubber bleb nevus syndrome (BRBNS) is a very rare condition. Herein we report the case of a 14-year-old girl who presented with chronic anemia that had required multiple blood transfusions and iron supplementation for many years. She had also received steroids. Physical examination revealed multiple small lesions on the dorsum of her feet ( $\bullet$ Fig. 1 ). Computed tomography (CT) of the abdomen showed multiple intraluminal lesions in the small bowel and colon (๑ Fig. 2).

A gastroscopy was performed ( $\mathbf{F i g . 3}$ ), followed by a colonoscopy and uneventful polypectomy of the colonic lesions (๑ Fig. 4; Video 1).

Histology revealed a cavernous hemangioma consistent with BRBNS. The patient underwent an exploratory laparotomy 1 week later during which she was found to have multiple lesions affecting the entire small bowel ( Fig.5), some of which had also caused intussusceptions of the small bowel.

An enterotomy was performed; she underwent further polypectomy of the internal lesions and resection of small-bowel wall to remove lesions that were involving the muscle layer. She was discharged from the hospital on the seventh postoperative day and 1 year later is doing well, having required no further blood transfusions. BRBNS was first reported by Gascoyen in 1860 [1] but the individual who made this disease famous was William Bennett Bean; it is also known as "Bean syndrome" [2]. The condition consists of multiple venous malformations that affect the skin and multiple visceral organs. The most common site for gastrointestinal tract involvement is the small bowel [3]. Skin lesions typically present at birth, whereas the gastrointestinal manifestations develop mostly in late adulthood. The commonest presenting symptom is spontaneous gastrointestinal bleeding, but the degree of bleeding may range from occult

\section{Video 1}

Colonoscopic polypectomy of the lesions in the colon was performed using a standard snare with electrocautery.

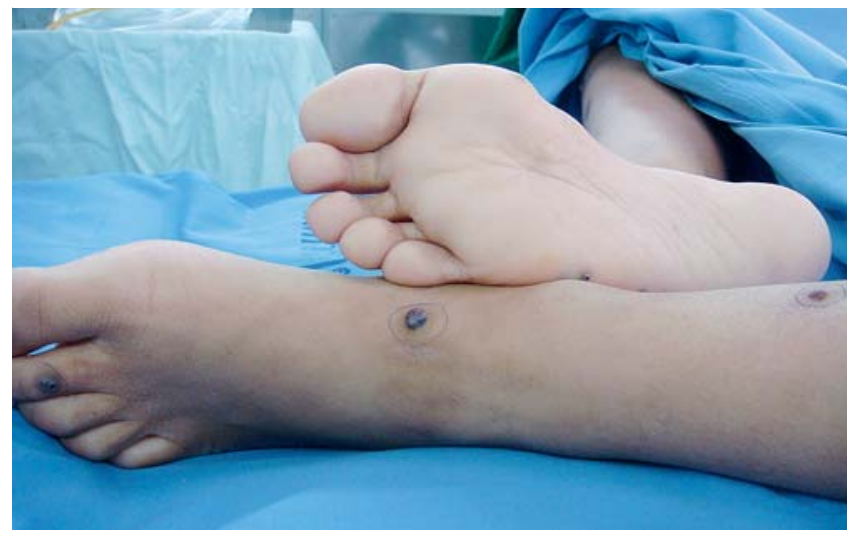

Fig. 1 Multiple small black cystic lesions on the feet of a 14-year-old girl who presented with chronic anemia due to blue rubber bleb nevus syndrome.
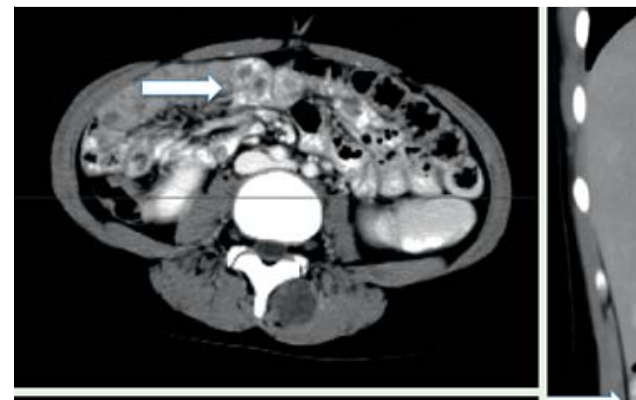
tions of endoscopic and surgical treatment, such as endoscopic polypectomy or injection [5], or enterotomy with excision of the small-bowel lesions [4] have been shown to be effective forms of management in refractory cases.

\section{Endoscopy_UCTN_Code_CCL_1AC_2AB}

\section{Competing interests: None}

\section{N. Suksamanapun ${ }^{1}$, A. Trakarnsanga ${ }^{2}$, T. Akaraviputh ${ }^{2}$}

Division of Pediatric Surgery, Department of Surgery, Faculty of Medicine Siriraj Hospital, Bangkok, Thailand
2 Minimally Invasive Surgery Unit, Division of General Surgery, Department of Surgery, Faculty of Medicine Siriraj Hospital, Bangkok, Thailand

\section{References}

1 Gascoyen M. Case of naevus involving the parotid gland, and causing death from suffocation. Naevi of the viscera. Trans Pathol Soc (Lond.) 1860; 11: 267

2 Bean WB. Bleeding from the gut in rare disorders with diagnostic lesions of the skin and mucous membranes. In: Bean WB ed. Rare diseases and lesions: their contributions to clinical medicine. Springfield, Illinois: Charles C. Thomas; 1967: 3-29

3 Gallo HG, McClave SA. Blue rubber bleb nevus syndrome: Gastrointestinal involvement and its endoscopic presentation. Gastrointest Endosc 1992; 38: 72 - 76 


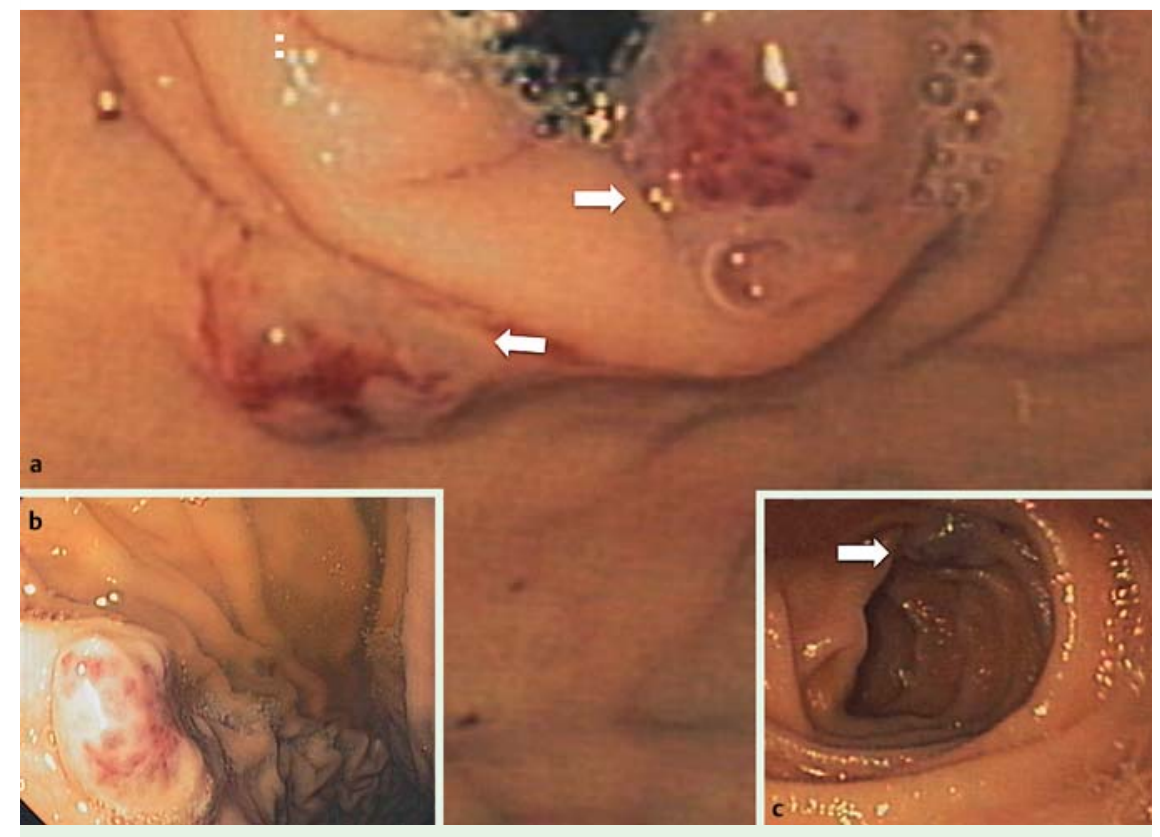

Fig. 3 Appearance at esophagogastroduodenoscopy showing multiple submucosal lesions (white arrows) in: $\mathbf{a}$ the fundus of the stomach; $\mathbf{b}$ the body of the stomach; $\mathbf{c}$ the duodenum.

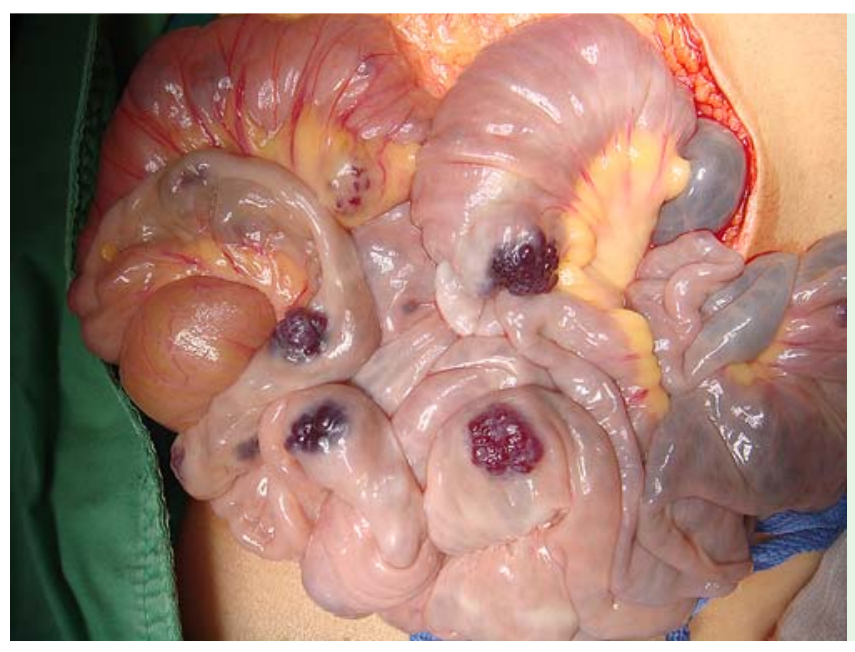

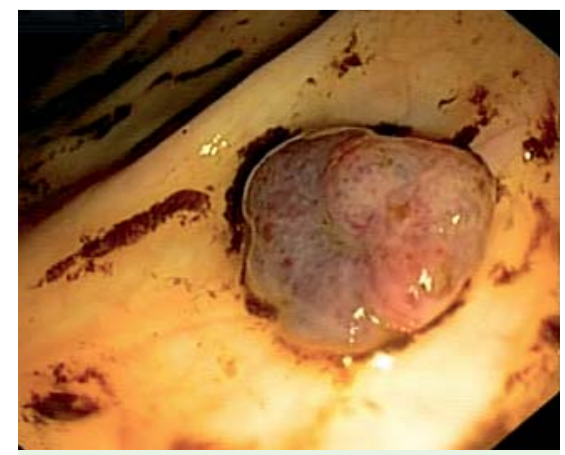

Fig. 4 Colonoscopic view showing one of the multiple small cystic polyps in the colon.

4 Fishman SJ, Smithers CJ, Folkman J et al. Blue rubber bleb nevus syndrome: Surgical eradication of gastrointestinal bleeding. Ann Surg 2005; 241: $523-528$

5 Dwiendi M, Misra SP. Blue rubber bleb nevus syndrome causing upper GI hemorrhage: a novel management approach and review. Gastrointest Endosc 2002; 55: 943 - 946

\section{Bibliography}

DOI $10.1055 / \mathrm{s}-0030-1257043$

Endoscopy 2011; 43: E411 -E412

(c) Georg Thieme Verlag KG Stuttgart · New York . ISSN 0013-726X

\section{Corresponding author}

\section{T. Akaraviputh, MD}

Minimally Invasive Surgery Center

Division of General Surgery

Department of Surgery

Faculty of Medicine Siriraj Hospital

Mahidol University

Bangkok 10700

Thailand

Fax: +66-2-4121370

sitak@mahidol.ac.th 